\title{
Modal parameters of the human hand-arm using finite element and operational modal analysis
}

\author{
S. Adewusi, M. Thomas ${ }^{\mathrm{a}}$, V.H. Vu And W. Li \\ Research Laboratory in Machinery, Process and Structural Dynamics (DYNAMO), Mechanical Engineering Department, École \\ de Technologie Superieure 1100 Notre-Dame Street West, Montreal, Quebec, H3C 1K3, Canada
}

Received 17 June 2013, Accepted 15 May 2014

\begin{abstract}
This study presents a finite element (FE) model of the human hand-arm system to derive natural frequencies and mode shapes. The FE model is calibrated by considering modal parameters obtained from experimental vibration analyzed by using operational modal analysis (OMA) and transmissibility. Modal and harmonic analyses of the FE model are performed for two boundary conditions. The first one considers fixed shoulder condition while the second one introduces the trunk in order to permit motion of the shoulder. The results show that the natural frequencies of the second model that permits shoulder motion are comparable with those determined from measurements. Especially, the natural frequency about $12 \mathrm{~Hz}$, which is corresponding to the frequency of maximum weight in ISO-5349-1 (2001), is not present in the model with fixed shoulder condition, while it appears in the second model. The results of the present study suggest that improved finite element models of the human hand-arm system may reveal hand-arm injury mechanism, the understanding of which may assist in deriving appropriate frequency weightings for the assessment of different components of the hand-arm vibration syndrome.
\end{abstract}

Key words: Hand-arm system / finite element / vibration measurements / ISO 5349-1

\section{Introduction}

Several epidemiological studies on workers exposed to prolonged hand-transmitted vibrations (HTV) have revealed various injurious effects like vascular, sensorineural and musculoskeletal disorders, generally referred to as the hand-arm vibration syndrome (HAVS) [1]. This has inspired research efforts about the dynamic characteristics of the human hand-arm system exposed to vibration (biodynamic responses) [2] and assessment of potential injury associated with prolonged exposure to HTV [3]. Although these research efforts have enhanced understanding of the health problems associated with occupational exposure to HTV and have led to several International Standards on how to measure, assess and mitigate the effects of HTV, the hand-arm injury mechanism due to vibrations is not yet fully understood. Furthermore, there are considerable discrepancies between injury assessments based on the current ISO 5349-1 [4] guidelines and epidemiological studies $[1,3,5]$. The development of a reliable hand-arm model may reduce variations in the reported biodynamic properties of the human handarm system and may enhance understanding of hand-

\footnotetext{
${ }^{a}$ Corresponding author: marc.thomas@etsmtl.ca
}

arm injury mechanism. Although the human hand-arm is a non-uniform, nonlinear, anisotropic and composite system, lumped-parameter models and continuous model based on beam theory have been developed to characterize biodynamic responses and energy absorption characteristics of the hand-arm substructures [6]. The authors of the studies [6] admitted that the lumped models did not represent the continuous fingers-hand-arm system and may not accurately predict location-specific responses. A recent study [7] presented biomechanical models of the hand-arm system, derived from both the driving-point mechanical impedance (DPMI) and transmissibility responses with the consideration of hand-arm arm postures and anatomical structure. However, the masses of the bones and muscles/tissues of the forearm and upper-arm of these models were lumped together to form rigid members. A very recent preliminary study has suggested that finite element (FE) models may provide the vital information needed to understand injury mechanism of the human hand-arm exposed to vibration, and reliable identification of hand-arm resonant frequencies [8]. The preliminary study however assumed a fixed shoulder condition with bones connected at joints with ligaments. These assumed conditions may not represent the actual condi- 


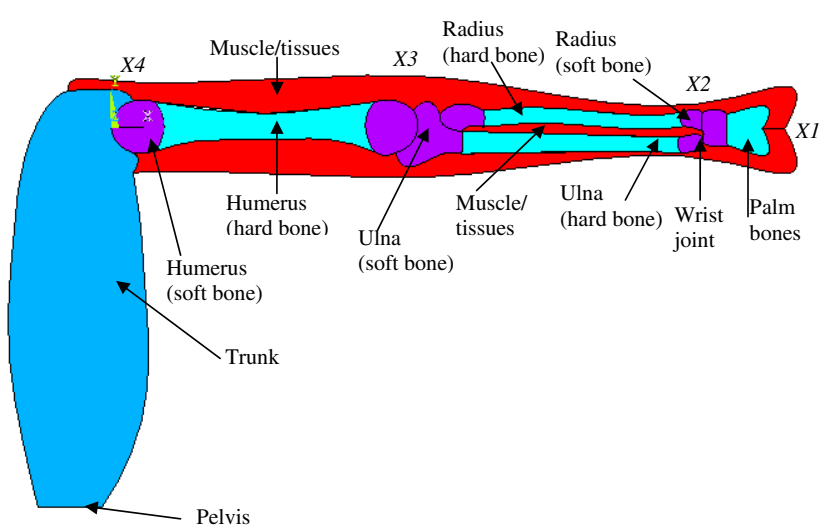

Fig. 1. Components and substructures of the human hand-arm FE model.

tions of the hand-arm of the operators of hand-held power tools.

The hypothesis of the present study is that finite element model of the human hand-arm system will yield reliable identification of the resonant frequencies and mode shapes of the hand-arm system. This study presents finite element (FE) model of the hand-arm system to determine the natural frequencies and mode shapes of different substructures of the human hand-arm. Two boundary conditions are imposed on the FE models namely: (1) the entire trunk is fixed to produce fixed shoulder condition, and (2) the trunk is fixed at the pelvis to permit motion of the shoulder. The natural frequencies of the FE model are also estimated from responses computed at different locations due to a simulated harmonic excitation considering damping. In order to calibrate these models and determine which model is more representative of the human hand-arm, the natural frequencies of the FE models are compared with those derived from measured transmissibility and those obtained from operational modal analysis (OMA). The autoregressive moving average (ARMA) technique as proposed by $\mathrm{Vu}$ et al. [9] has been applied to experimental acceleration measurements using output only.

\section{Methods}

\subsection{Finite element (FE) model}

Two-dimensional (2D) FE model of the human handarm, which consists of the palm, forearm, upper-arm and the joints, is presented in Figure 1. The fingers are not considered since a few studies [10] have presented the 2D FE model of the fingertip, which may be considered as a representative model of the fingers. Figure 1 presents the hand-arm model in the extended arm posture consisting of the trunk, humerus bone, radius and ulna bones, bones of the palm (carpals bones lumped together), and muscles/tissues.

The humerus, radius and ulna bones consist of the cortical (hard) bone around the mid-span and trabecular (soft) bones at the ends. The bones are assumed
Table 1. Dimensions of the hand-arm of six subjects.

\begin{tabular}{lccc}
\hline \multicolumn{3}{c}{ Hand-arm length and projected dimensions on a plane } \\
\hline Parameters & Ranges & Mean & STD \\
\hline Age (years) & $26-53$ & 36.5 & 11.33 \\
Height $(\mathrm{cm})$ & $171-180$ & 174.0 & 0.02 \\
Weight $(\mathrm{kg})$ & $61-86$ & 72.2 & 9.87 \\
BMI & $20.4-28.7$ & 23.8 & 3.13 \\
Hand length $(\mathrm{cm})$ & $17-20.5$ & 18.4 & 1.20 \\
Hand width at thumb (cm) & $9.5-12.0$ & 10.9 & 0.86 \\
Hand width at metacarpal $(\mathrm{cm})$ & $7.0-8.5$ & 7.5 & 0.63 \\
Hand thickness $(\mathrm{cm})$ & $2.0-3.7$ & 2.9 & 0.55 \\
Wrist width $(\mathrm{cm})$ & $5.1-5.9$ & 5.5 & 1.04 \\
Forearm width $(\mathrm{cm})$ & $8.0-10.0$ & 8.9 & 2.53 \\
Elbow width $(\mathrm{cm})$ & $7.8-9.7$ & 8.4 & 2.22 \\
Forearm length $(\mathrm{cm})$ & $24.0-28.5$ & 26.0 & 1.58 \\
Upper arm width $(\mathrm{cm})$ & $8.9-10.5$ & 9.0 & 3.13 \\
Upper arm length $(\mathrm{cm})$ & $23.0-32.0$ & 28.5 & 2.35 \\
\hline
\end{tabular}

to be in contact at joints and then held together by muscles/tissues. The mean anthropometric dimensions (Tab. 1) of the hand-arm of 6 subjects who participated in the laboratory measurements of transmissibility responses of the human hand-arm system exposed to $z_{h}$-axis vibration [11] and the reported bone dimensions were used to develop the FE model in ANSYS using the SI system of units. $X 1, X 2, X 3$ and $X 4$ represent in Figure 1, locations near the palm, wrist, elbow and shoulder, respectively, where responses of the model are observed. Most of the laboratory studies on effects of hand-arm posture on the biodynamic responses considered either the bent-arm $\left(90^{\circ}\right.$ elbow angle) or the extended arm $\left(180^{\circ}\right.$ elbow angle) postures $[2,11]$. Furthermore, the posture (about $155^{\circ}$ elbow angle with about $30^{\circ}$ abduction angle) of the operator of road breakers is close to the extended arm posture (180 ${ }^{\circ}$ elbow angle). Although the posture assumed by an operator of the hand-held power tool depends on the type of tool and the kind of the operation being performed, the extended hand-arm posture, as shown in Figure 1, is modeled in this study for simplicity and in order to compare the FE model results with available experimental data.

\subsubsection{FE model with fixed shoulder}

The majority of the reported lumped-parameter models assumed a fixed shoulder condition even though some studies have reported substantial vibration at the shoulder $[11,12]$; motion of the trunk and the head was also reported in extended arm posture [13]. The fixed shoulder condition of the first model is achieved in this study by applying fixed boundary condition (zero displacement) to the entire trunk so that is does not move.

\subsubsection{FE model with motion of the shoulder}

The second model with the relaxation of the fixed shoulder condition to permit the motion of the shoulder is obtained by changing the boundary condition imposed 
Table 2. Mechanical properties of the components of the human hand-arm system.

\begin{tabular}{lccc}
\hline & Cortical bone & Trabecular bone & Muscles/tissues \\
\hline Young modulus (MPa) & $7230-17000$ & $43.6-1060$ & $345-888$ \\
Poisson ratio & 0.3 & 0.3 & 0.3 \\
Density $\left(\mathrm{kg} . \mathrm{m}^{-3}\right.$ ) & $1.5-2.0 \times 10^{3}$ & $1.0-7.0 \times 10^{3}$ & $0.75-1.2 \times 10^{3}$ \\
\hline
\end{tabular}

on the model in Figure 1. Fixed boundary condition is applied at the pelvis only to allow for motion of the trunk and hence the shoulder. All the components of the human trunk (spines, scapular, abdomen, etc.) are lumped together as shown in Figure 1 to simplify the model and since this study focuses on the hand-arm.

\subsubsection{Modal and harmonic analyses of FE models}

The ranges of the reported values for the mechanical properties of cortical and trabecular bones, and muscles/tissues [14-16], as summarized in Table 2, are used for the FE simulations using ANSYS. Although the reported properties of bones are for the femur bone, the properties of the hand-arm bones are assumed to be similar to those of the femur. Plane182 element type is used for the tissues/muscles since this element type has plasticity, hyper-elasticity, stress stiffening, large deflection, and large strain capabilities. Other components are represented with Plane183 element type, which is good for modeling irregular shapes. The FE analysis is performed in two steps using ANSYS. The first step consists of harmonic analysis of the model that permits motion of the shoulder when an excitation force of $50 \mathrm{~N}$ in the $z_{h}$-axis direction is applied at the palm side. A force of $50 \mathrm{~N}$ was applied because the transmissibility responses reported in [11] correspond to $50 \mathrm{~N}$ push and $30 \mathrm{~N}$ grip forces. It should be noted that the $x$ - and $y$-axis in ANSYS correspond to the $z_{h^{-}}$and $y_{h}$-axis, respectively, of the handarm coordinate system defined in ISO 5349-1 [4].

Rayleigh damping coefficients are estimated from the resonant frequencies and damping ratios obtained from measured transmissibility responses using half-power concept and those obtained from operational modal analysis (OMA) of the measured acceleration time signals. During the simulations, the mechanical properties of the trunk and muscles/tissues are varied while the lower values of Young modulus and higher values of density of the bones were maintained until some of the resonant frequencies of the model are comparable with those obtained from OMA using autoregressive moving average (ARMA) technique. The properties of the trunk and muscles are varied since mechanical properties of the trunk are not known and the properties of the muscles/tissues depend on hand forces and hand-arm posture. The harmonic responses are computed at four different locations marked $X 1-X 4$ on Figure 1. These responses correspond to deformations, in the frequency domain, around the palm side $(X 1)$, the wrist $(X 2)$, the elbow $(X 3)$ and the shoulder $(X 4)$. The mechanical properties obtained are used for all other analyses with different boundary conditions. The second step is the modal analysis to determine the natural frequencies and mode shapes of the model for fixed shoulder condition and the condition that permits motion of the shoulder. The natural frequencies of the two models are compared to study the effect of boundary condition of the shoulder on the natural frequencies of the hand-arm system in the extended arm posture.

\subsection{Estimation of resonant frequencies from measured transmissibility responses}

Laboratory experiments have been performed to measure the transmissibility responses of the human handarm of six male subjects in the bent-arm and extended arm postures at the wrist, elbow and shoulder, as shown in Figure 2. An instrumented handle of diameter $40 \mathrm{~mm}$ with force sensors and accelerometers to measure hand forces and input excitation is attached to an electrodynamic shaker. A broadband random excitation in the $2.5-2500 \mathrm{~Hz}$ frequency range with $\mathrm{rms}$ acceleration value of $5.25 \mathrm{~m} . \mathrm{s}^{-2}$ was used to excite the handle in the $z_{h}$-axis while six male subjects gripped the handle in turn with $30 \mathrm{~N}$ grip and $50 \mathrm{~N}$ push forces. The vibration transmitted to different locations on the hand-arm was measured using tri-axial PCB accelerometers attached to Velcro strips, which were tightly fastened near the joints so as to minimize the contributions due to skin artifacts. Accelerations along the $y_{h^{-}}$and $z_{h^{-}}$-axes were measured at locations. A 12-channel 01dB Stell data acquisition system and dBRTA/dBFA32 data analysis software by $01 \mathrm{~dB}$ Metravib were used. The sampling frequency was $6400 \mathrm{~Hz}$. The coherence of the measurements was also monitored during the experiments to ensure reliability of the measured data. Each measurement was repeated three times. Detailed results were published in [11]. In the present study, the measured acceleration time signals are analyzed by OMA analysis, as described in Section 2.3. Furthermore, the transmissibility responses are re-analyzed for each subject to derive the resonant frequencies of each subject. In the previous study [11], resonant frequencies were derived from the mean transmissibility responses of the six subjects.

\subsection{Estimation of modal parameters by using operational modal analysis (OMA)}

The technique of operational modal analysis (OMA) by using the auto-regressive moving average (ARMA) technique and developed by $\mathrm{Vu}$ et al. [9] was used to estimate the natural frequencies and damping ratios of 


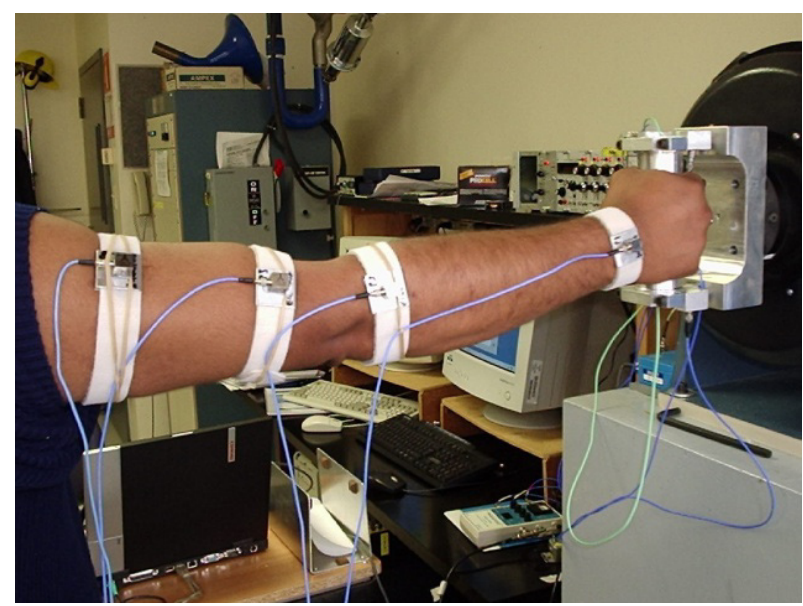

Fig. 2. Experimental set-up showing the extended arm posture.

the hand-arm system using experimentally measured acceleration time signals, as described in Section 2.2. The acceleration time signals in the $y_{h}$-and $z_{h}$-axis at different locations (wrist, elbow and shoulder) in the experimental study on transmissibility of an extended arm shown in Figure 2 are used as inputs to the Matlab code for the OMA using ARMA developed in [9]. Although the ARMA method was developed for situations where it is difficult or impossible to measure the input, it may also be used on laboratory measurements for improved identification of modal parameters of the human hand-arm. The ARMA method has been shown to give reliable estimates of modal parameters [9]. The concept of ARMA is briefly outlined in this section. If the time signals of a dynamic system are simultaneously measured at different locations using $d$ channels with a sampling time $T_{s}$, then a multivariate ARMA model of order $p$ and dimension $d$ to estimate the time signals may be developed such that:

$$
\{y(t)\}_{d \times 1}=[\Phi]_{d \times d p}\{\varphi(t)\}_{d p \times 1}+\{e(t)\}_{d \times 1}
$$

where $\{y(t)\}_{d \times 1}$ is the output vector,

$$
[\Phi]_{d \times d p}=\left[-\left[a_{1}\right]-\left[a_{2}\right] \ldots-\left[a_{i}\right] \ldots-\left[a_{p}\right]\right]
$$

is the matrix of the model parameters of size $d \times d p$,

$$
[\varphi]_{d p \times 1}=[y(t-1) ; y(t-2) ; \ldots ; y(t-p)]
$$

is the regressor of size $d p \times 1$, and $\{e(t)\}_{d \times 1}$ is the residual.

For $N$ consecutive outputs of the responses from $\{y(t)\}$ to $\{y(t+N-1)\}$, the model parameters can be estimated using the least squares with QR factorization method [27]. The model is then converted to the statespace form for frequency and damping calculations, the state matrix is given as:

$$
\left.A\right|_{d p \times d p}=\left[\begin{array}{ccccc}
-a_{1} & -a_{2} & -a_{3} & \ldots & -a_{p} \\
I & 0 & 0 & \ldots & 0 \\
0 & I & 0 & \ldots & 0 \\
\ldots & \ldots & \ldots & \ldots & \ldots \\
0 & 0 & 0 & I & 0
\end{array}\right]
$$

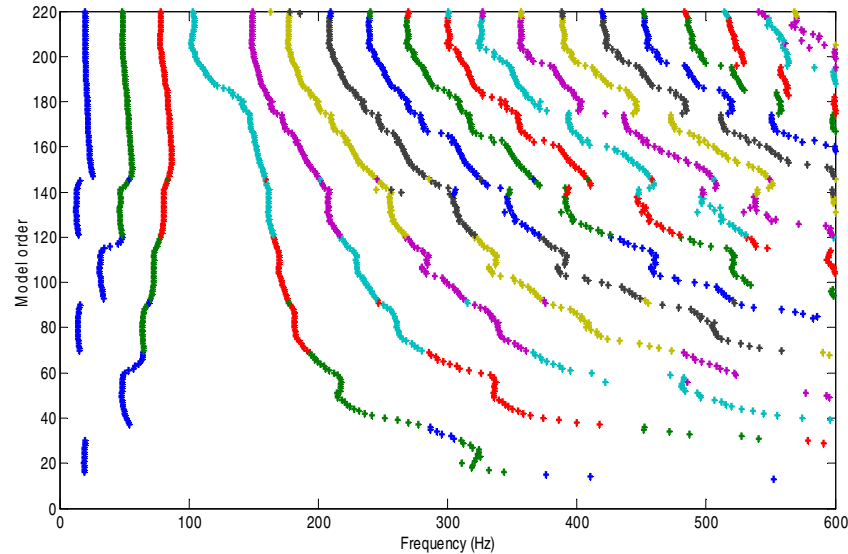

Fig. 3. Frequency stability diagram from OMA analysis.

The eigenvalue problem is then solved to determine the eigenvalues $\lambda_{i}$, circular frequencies $\omega_{i}$, resonance frequencies $f_{i}$ and the damping ratios $\xi_{i}$ of the dynamic system such that:

$$
\begin{aligned}
{[V \lambda] } & =\operatorname{eig}(A) \\
\omega_{i} & =\sqrt{\operatorname{Re}^{2}\left(\lambda_{i}\right)+\operatorname{Im}^{2}\left(\lambda_{i}\right)} ; \quad f_{i}=\frac{\omega_{i}}{2 \pi} \\
\xi_{i} & =-\frac{\operatorname{Re}\left(\lambda_{i}\right)}{\omega_{i}}
\end{aligned}
$$

Figure 3 shows an example of the frequency stability diagram from which resonant frequencies are identified.

The OMA-ARMA matlab code is interactive and it permits users to specify the maximum frequency of interest and identify the best order $p$ of the model. A maximum frequency of $600 \mathrm{~Hz}$ and a $p$ of 220 were used for the analysis. The natural frequencies and damping ratios for each of the six subjects were obtained from the frequency and damping stability diagrams; the mean of these values is then calculated. We must notice that the human cannot be considered as a stationary system and that the natural frequencies may vary in time. Some of the resonant frequencies and damping ratios are used to estimate the Rayleigh damping coefficients, which are used for the harmonic analysis of the model in ANSYS. Resonant frequencies are then estimated from the FE harmonic responses of the models at the palm, wrist, elbow and shoulder.

\section{Results and discussion}

\subsection{Natural frequencies and mode shapes of the hand-arm system}

The first twenty natural frequencies of the FE model for the two boundary conditions are presented in Table 3 with remarks about which substructure has maximum deformation, as observed from the animation of the mode shapes in ANSYS.

The first twenty natural frequencies are considered to focus on $0-500 \mathrm{~Hz}$ frequency range. Figure 4 presents the first eight mode shapes of the model that permits the motion of the shoulder. 
Table 3. Natural frequencies of the hand-arm models with fixed shoulder and moving shoulder.

\begin{tabular}{cclll}
\hline & Model with fixed shoulder & Model that permits shoulder motion \\
\hline Mode \# & Freq. (Hz) & Remarks (highest at) & Freq. (Hz) & Remarks (highest at) \\
\hline 1 & 8.2 & Rigid rotation & 5.3 & Rigid rotation about the shoulder \\
2 & 39.0 & Elbow & 13.4 & All parts $\left(z_{h}\right.$-axis) \\
3 & 111.3 & Palm & 34.7 & Elbow \\
4 & 131.4 & All parts $\left(z_{h}\right.$-axis) & 96.2 & All parts \\
5 & 190.2 & All parts & 107.5 & Palm \\
6 & 329.4 & All parts & 123.3 & Palm and wrist \\
7 & 342.9 & All joints & 184.1 & All parts \\
8 & 411.4 & Wrist \& palm & 191.2 & All parts $\left(z_{h}\right.$-axis) \\
9 & 459.5 & Wrist \& elbow $\left(z_{h}\right.$-axis) & 251.1 & All joints \\
10 & 576.9 & All parts & 304.5 & Shoulder and elbow \\
11 & 642.5 & Palm muscle & 381.9 & All parts \\
12 & 700.7 & Forearm \& palm & 385.0 & Palm \\
13 & 710.4 & Palm & 402.4 & Wrist and palm \\
14 & 769.7 & Elbow & 456.2 & Wrist and palm $\left(z_{h}\right.$-axis) \\
15 & 815.4 & Elbow and palm $\left(y_{h}\right.$-axis) & 466.9 & Elbow \& Palm \\
16 & 844.2 & Palm (mostly muscles) & 549.1 & All joints \\
17 & 846.4 & Upper-arm & 553.4 & All joints and palm muscles \\
18 & 904.6 & Palm, wrist and elbow muscles & 609.8 & Elbow and palm muscles \\
19 & 932.3 & Upper-arm muscles & 616.5 & Trunk \\
20 & 953.7 & Shoulder and elbow muscles & 642.6 & Palm muscles \\
\hline
\end{tabular}

Table 3 shows substantial differences in the natural frequencies and the mode shape pattern for the model with a fixed shoulder and the model with shoulder motion. The natural frequencies of the model with a fixed shoulder are generally higher, suggesting that a fixed shoulder boundary condition stiffens the hand-arm system. For the model with fixed shoulder conditions, a mode around $13.0 \mathrm{~Hz}$, which is closed to the frequency $(12.5 \mathrm{~Hz})$ of the maximum weight in the current ISO 5349-1 [9] frequency weighting, is not present. The model that permits shoulder motion exhibits a mode around $13.4 \mathrm{~Hz}$ (2nd mode), which is close to the frequency of the maximum weight in the current ISO weighting. Figure 4 shows that the first mode corresponds to a rigid rotation of the entire hand-arm system about the shoulder. This mode, which is common to both models, may be difficult to detect in the laboratory measurements of biodynamic responses for the extended-arm posture because the hand gripping the handle is constrained to move in the $z_{h}$-axis when uniaxial $z_{h}$-axis excitation is used, as shown in Figure 2 . This mode, however, may be easily detected in measured biodynamic responses when the hand-arm is excited in the $y_{h}$-axis direction. Furthermore, the reported eigen analysis of different lumped-parameter models of the handarm derived from biodynamic responses showed that most of the models have their first natural frequencies in the $2.2-4.6 \mathrm{~Hz}$ range in the $z_{h}$-axis direction [6].

Table 3 and Figure 4 show that the 2nd mode $(13.3 \mathrm{~Hz}), 8$ th mode $(191.2 \mathrm{~Hz})$ and 14 th mode $(456.2 \mathrm{~Hz})$ are predominantly motion in the $z_{h}$-axis direction. The human hand-arm system may be subjected to repeated extension and compression, particularly at the joints, when excited at these modal frequencies and this may cause joint injury and musculoskeletal disorder. An interesting observation in Figure 4 is that the forearm and the upper-arm have higher natural frequencies (above $100 \mathrm{~Hz}$ ). The study associated low natural frequencies $(3.8,12.7,33.6 \mathrm{~Hz})$ to the arms. The reported natural frequencies $112.5 \mathrm{~Hz}$ and $119.7 \mathrm{~Hz}$ are comparable with the 6 th mode $(107.5 \mathrm{~Hz})$ and 7 th mode $(123.3 \mathrm{~Hz})$, respectively in Table 3, which are associated with the wrist and palm. The present study clearly shows that the forearm and upper-arm also have high natural frequencies (above $100 \mathrm{~Hz}$ ), which are not evident in the results of the lumped-parameter models probably due to limited degree-of-freedom (DOF). The maximum DOF in the reported lumped-parameter model was seven [7].

\subsection{Comparisons of resonant frequencies of the models with those from experimental data}

The resonant frequencies and damping ratios for the six subjects are derived from the stability diagrams of the OMA-ARMA analysis. An example of the frequency stability diagram is presented in Figure 3. The resonant frequencies are also obtained from the measured transmissibility responses, as explained in Section 2.2. Finally, the resonant frequencies of the $\mathrm{FE}$ models are obtained from harmonic responses at four different locations around the palm, wrist, elbow and shoulder designated as $X 1-X 4$ on Figure 1 in both the $z_{h^{-}}$and $y_{h^{-}}$axis.

Figure 5 illustrates the harmonic responses at different locations on the hand-arm model with shoulder motion in the $z_{h}$-axis. The responses are presented in both the linear (Fig. 5a) and logarithmic (Fig. 5b) scales to respectively highlight responses in low and high frequencies regions. The responses are considered on the muscles/tissues (e.g. Palm_m) and on the bone structures (e.g. Palm_b). Figure 5 shows that there is small difference between the bone structures and muscles/tissues responses below 


\section{SOIB $=1$}

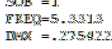

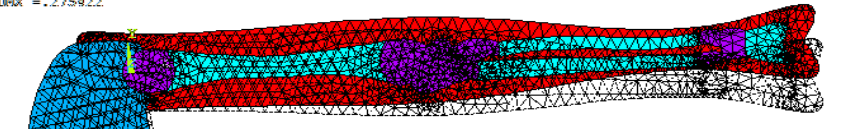

(a)

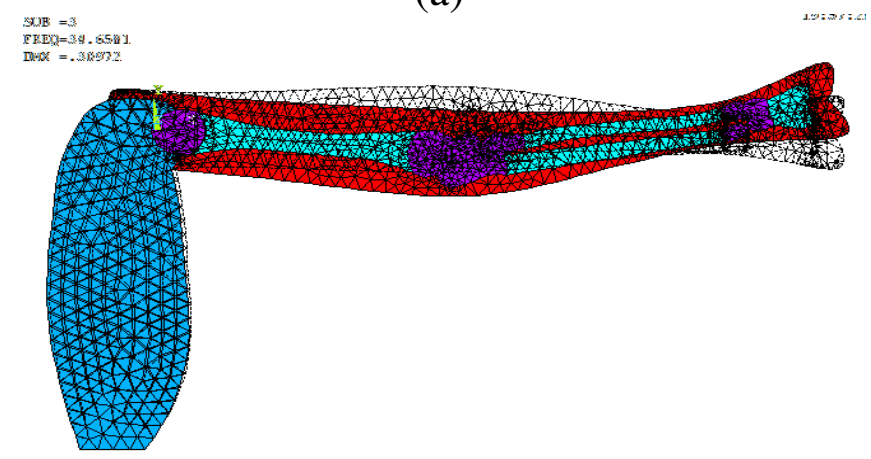

(c)

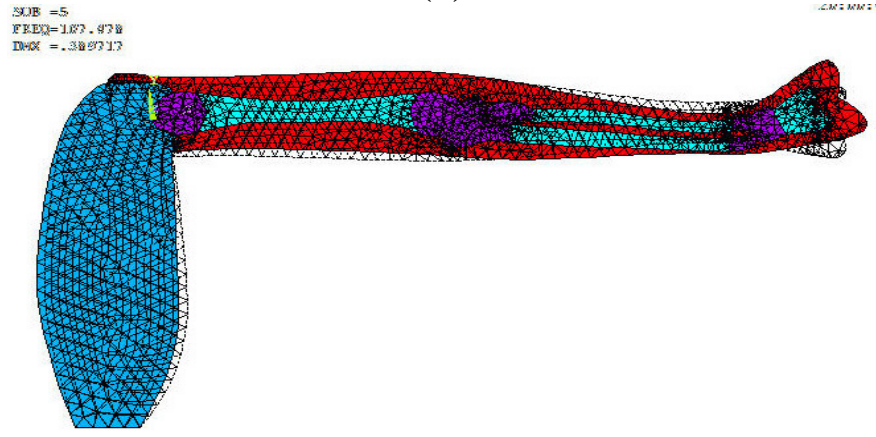

(e)

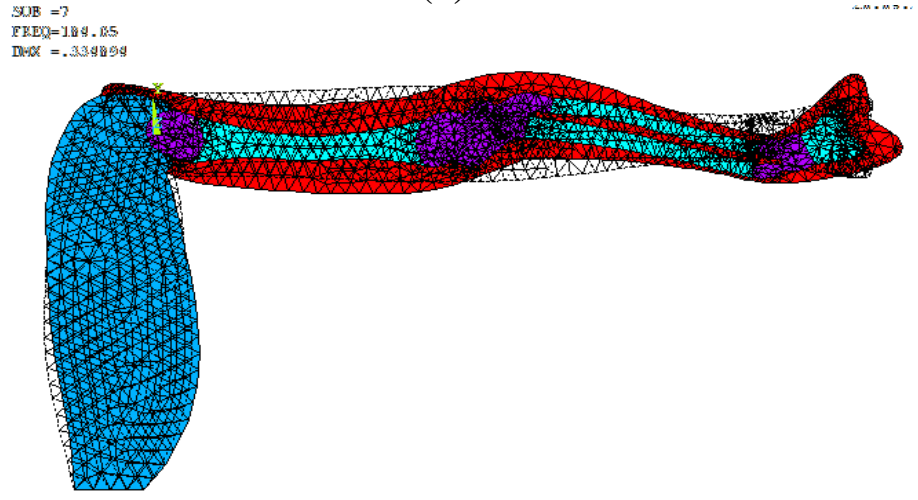

(g)

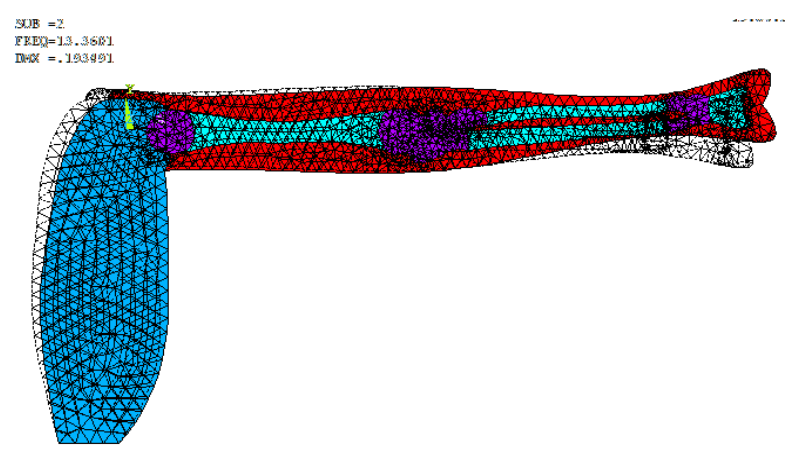

(b)

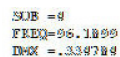

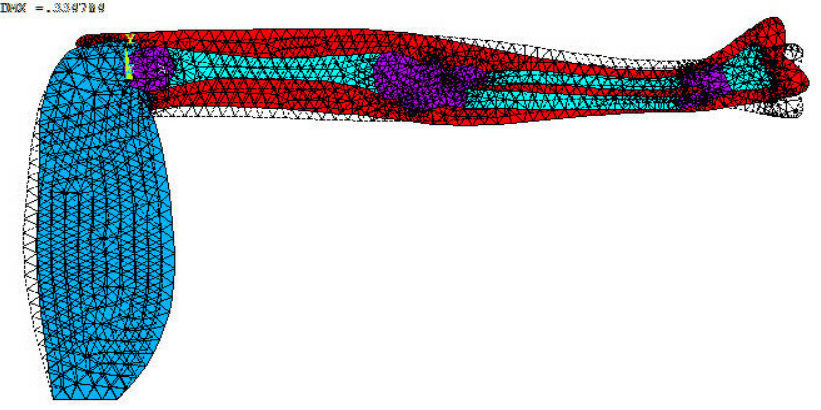

(d)

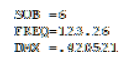

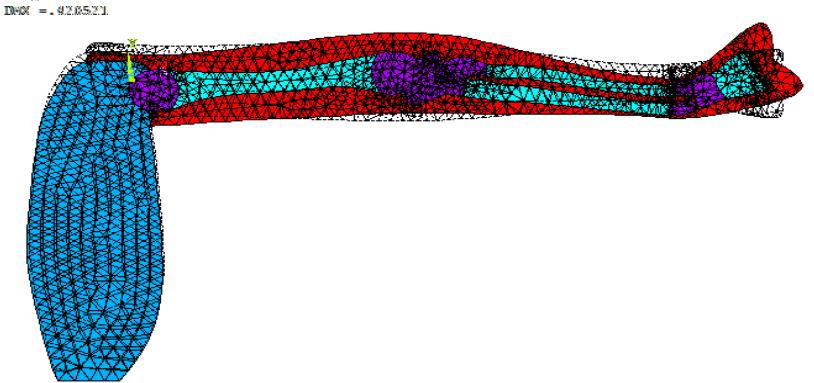

(f)

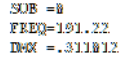

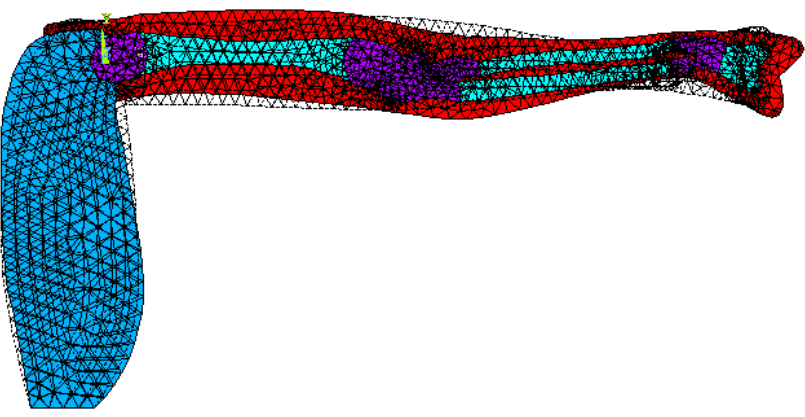

(h)

Fig. 4. Mode shapes of the hand-arm model that permits shoulder motion; (a) 1st mode at $5.3 \mathrm{~Hz}$; (b) 2nd mode at $13.4 \mathrm{~Hz}$; (c) 3 rd mode at $34.7 \mathrm{~Hz}$; (d) 4 th mode at $96.2 \mathrm{~Hz}$; (e) 5 th mode at $107.5 \mathrm{~Hz}$; (f) 6th mode at $123.3 \mathrm{~Hz}$; (g) 7 th mode at $184.1 \mathrm{~Hz}$; and (g) 8th mode at $191.2 \mathrm{~Hz}$. 


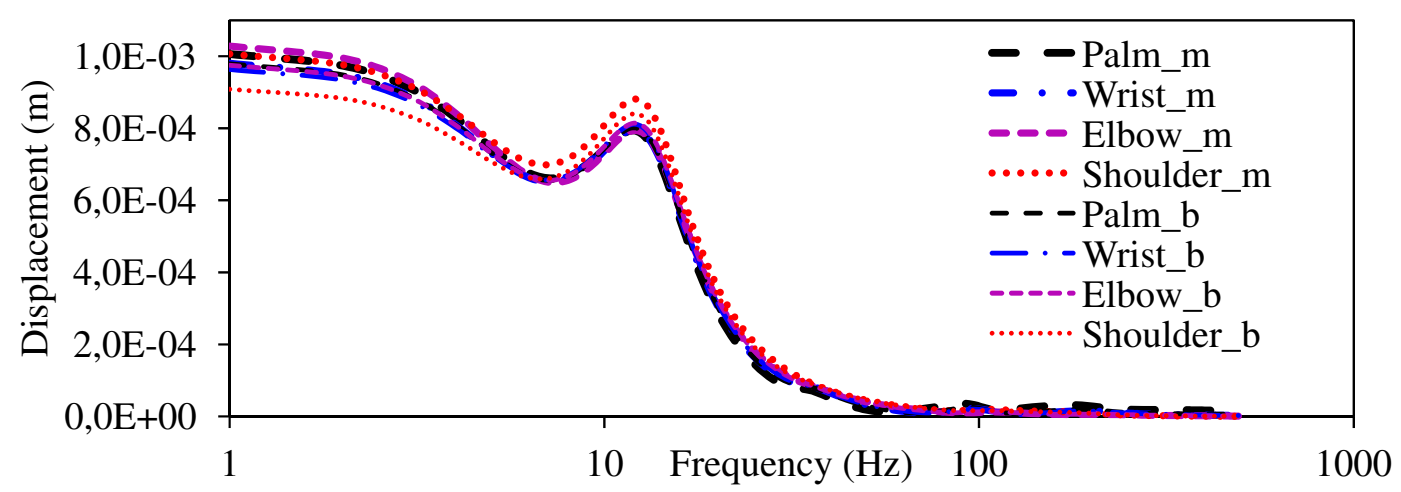

(a)

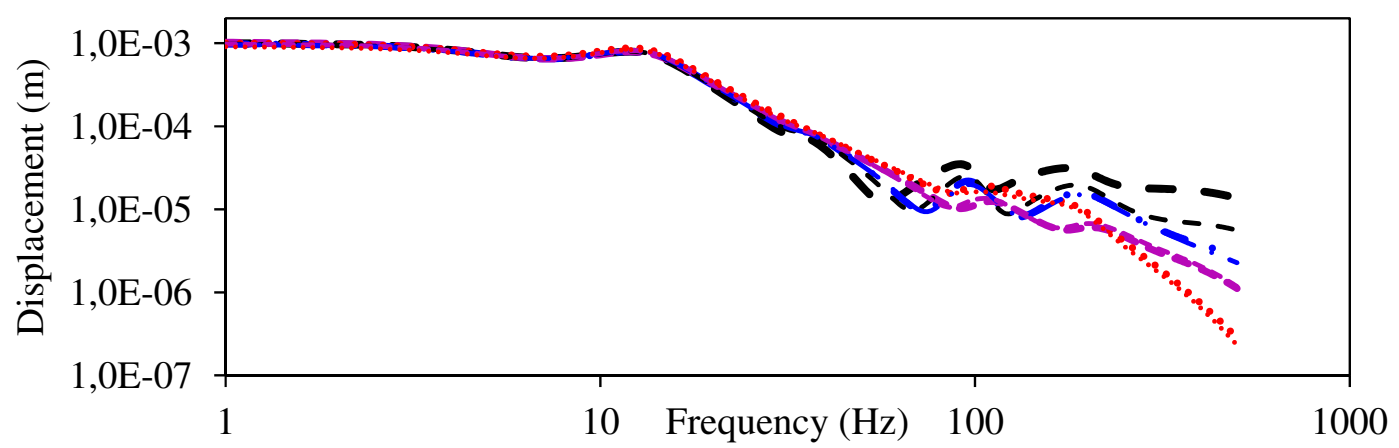

(b)

Fig. 5. Harmonic responses in the $z_{h}$-axis of bones and muscles for the FE model that permits shoulder motion around the palm $(X 1)$, wrist $(X 2)$, elbow $(X 3)$ and shoulder $(X 4)$; (a) linear scale of magnitude; (b) logarithmic scale of magnitude.

$15 \mathrm{~Hz}$ for the shoulder responses and above $40 \mathrm{~Hz}$ for the palm responses; the responses at other locations are almost the same at all frequencies. Furthermore, Figure 5 shows small amplification of the elbow muscles response below $4 \mathrm{~Hz}$ and shoulder muscles response between 4 and $72 \mathrm{~Hz}$. This trend is similar to that observed in the reported measured transmissibility responses, where amplification of the elbow and shoulder responses was reported below $15 \mathrm{~Hz}$ for the extended arm posture [11].

The resonant frequencies estimated from the measured transmissibility responses, and the harmonic responses of the FE models in the $y_{h^{-}}$and $z_{h^{-}}$axis are summarized in Table 4 for comparison. As observed in Table 3, the resonant frequencies derived from the FE model with a fixed shoulder are generally higher compared to the model that permits shoulder motion. A frequency about $12 \mathrm{~Hz}$ is conspicuous in the responses of the model that permits shoulder motion but not in the responses of the fixed shoulder model. Also, Figure 5b shows that the entire hand-arm system is excited in the $z_{h}$-axis around $12 \mathrm{~Hz}$, and the animation of the 2 nd mode $(13.4 \mathrm{~Hz})$ showed that the motion and deformation are predominantly in the $z_{h^{-}}$ axis, which results in continuous extension/compression of the joints and may cause the injury of the joints. This frequency $(12 \mathrm{~Hz})$ is close to the $12.5 \mathrm{~Hz}$, which is the frequency with the maximum weight in the ISO 5349-1 [9] frequency weighting.

Some studies have suggested that the ISO 5349-1 [9] frequency weighting is good for assessing injury of the joints and musculoskeletal disorder in the arms of operators of low frequency power tools (e.g. sand rammers) who normally complain of pain in the arms, shoulder, neck and the head [17]. The 1st mode (about $3 \mathrm{~Hz}$ ) is not very conspicuous in the measured transmissibility and harmonic responses of the FE models, and OMA-ARMA results. This may be attributed to the restriction of the excitation to $z_{h}$-axis, the hand-arm damping and the fact that the 1 st mode is a rigid rotational motion about the shoulder. This frequency may be seen in the responses for excitation in the $y_{h}$-axis. Furthermore, the FE models did not show some resonant frequencies that are present in the measured transmissibility responses and the OMAARMA method (Tab. 5) probably due to the linearity assumptions in the FE modeling whereas the human handarm model is a highly non-linear system.

This suggests that the FE models need to be fine tuned since the mechanical properties of the human handarm system change with hand forces and posture. This may be achieved by slightly changing the reported mechanical properties of the hand-arm system until the FE models' responses are close to measured biodynamic responses. The results show that the FE model which permits shoulder motion is better than the model with a fixed shoulder since the former yields more frequencies that are comparable with frequencies derived from the measured experimental data. The following ranges of frequencies are common to the measured transmissibility responses, harmonic responses of the $\mathrm{FE}$ model that permits shoulder 
Table 4. Resonant frequencies of the hand-arm system from the measured transmissibility responses and the harmonic responses of the finite element (FE) models.

\begin{tabular}{|c|c|c|c|c|c|c|c|}
\hline \multicolumn{4}{|c|}{ Measured Transmissibility } & \multicolumn{2}{|c|}{$\begin{array}{l}\text { FE model with } \\
\text { fixed shoulder }\end{array}$} & \multicolumn{2}{|c|}{$\begin{array}{l}\text { FE model with } \\
\text { shoulder motion }\end{array}$} \\
\hline \multicolumn{2}{|c|}{$z_{h}$-axis } & \multicolumn{2}{|c|}{$y_{h}$-axis } & \multirow{2}{*}{$\frac{z_{h} \text {-axis }}{(\mathrm{Hz})}$} & \multirow{2}{*}{$\frac{y_{h} \text {-axis }}{(\mathrm{Hz})}$} & \multirow{2}{*}{$\frac{z_{h} \text {-axis }}{(\mathrm{Hz})}$} & \multirow{2}{*}{$\frac{y_{h} \text {-axis }}{(\mathrm{Hz})}$} \\
\hline Ranges $(\mathrm{Hz})$ & Mean $(\mathrm{Hz})$ & Ranges $(\mathrm{Hz})$ & Mean $(\mathrm{Hz})$ & & & & \\
\hline \multicolumn{4}{|c|}{ Wrist } & \multicolumn{4}{|c|}{ Wrist } \\
\hline $2.3-3.1$ & 2.6 & $2.3-3.1$ & 2.7 & & & & \\
\hline $7.0-7.8$ & 7.4 & $4.7-9.4$ & 7.1 & & & 12.0 & 12.0 \\
\hline $10.4-14.8$ & 11.9 & $18-25.6$ & 21.2 & 36.0 & 37.0 & 36.0 & 33.0 \\
\hline $21.1-23.4$ & 22.5 & $30.4-39.8$ & 36.6 & 127.0 & 127.0 & 96.0 & 104.0 \\
\hline $42.2-44.5$ & 43.7 & $59.4-78.9$ & 69.3 & & 304.0 & 191.0 & 245.0 \\
\hline $93.8-127.3$ & 106.3 & $114.8-129.7$ & 123.2 & & & & 400.0 \\
\hline $143.0-179.7$ & 165.1 & $200.0-230.0$ & 215.0 & \multirow{2}{*}{\multicolumn{4}{|c|}{ Elbow }} \\
\hline $222.7-280.5$ & 251.6 & $341.1-342.9$ & 342.0 & & & & \\
\hline $362.5-370.0$ & 366.3 & $400.0-417.2$ & 408.6 & & 39.0 & 12.0 & 12.0 \\
\hline \multirow[t]{3}{*}{$422.7-452.3$} & 437.5 & & & 128.0 & 107.0 & 111.0 & 113.0 \\
\hline & \multirow{2}{*}{\multicolumn{2}{|c|}{ Elbow }} & & 270.0 & 202.0 & 209.0 & 185.0 \\
\hline & & & & & 357.0 & & \\
\hline $2.3-3.9$ & 2.8 & $2.3-3.1$ & 2.9 & & & & \\
\hline $7.8-11.7$ & 10.6 & $5.5-8.6$ & 6.7 & \multicolumn{4}{|c|}{ Shoulder } \\
\hline $15.6-18.8$ & 16.6 & $10.2-11.7$ & 10.8 & & & 12.0 & 12.0 \\
\hline $21.9-25.9$ & 23.5 & $14.1-18.8$ & 16.0 & 41.0 & 41.0 & & 33.0 \\
\hline $28.1-36.7$ & 32.4 & $31.3-35.9$ & 34.2 & 128.0 & 135.0 & 103.0 & 97.0 \\
\hline $61.7-71.1$ & 66.4 & $54.5-81.3$ & 65.3 & 330.0 & 329.0 & 178.0 & 179.0 \\
\hline $91.4-112.5$ & 103.0 & $91.4-105.0$ & 100.1 & & & & \\
\hline $128.9-164.8$ & 144.5 & $264.2-297.7$ & 278.2 & \multicolumn{4}{|c|}{ Palm } \\
\hline \multirow[t]{3}{*}{$241.2-248.4$} & 244.8 & $362.5-369.5$ & 366.0 & & & 12.0 & 12 \\
\hline & & & & 36 & 37 & 35.0 & 33.0 \\
\hline & Shoulder & & & 119 & 105 & 92.0 & 94.0 \\
\hline $2.3-3.9$ & 3.5 & $3.1-3.9$ & 3.5 & & 166 & 179.0 & \\
\hline $6.3-7.0$ & 6.8 & $6.3-9.4$ & 7.7 & 335 & 348 & & \\
\hline $10.2-11.7$ & 10.9 & $11.7-17.2$ & 13.5 & & & & \\
\hline $14.1-17.2$ & 15.7 & $21.1-28.9$ & 24.8 & & & & \\
\hline $38.3-42.2$ & 40.3 & $35.2-39.1$ & 37.2 & & & & \\
\hline $50.0-54.7$ & 52.4 & $48.4-53.9$ & 50.2 & & & & \\
\hline $73.4-79.7$ & 76.6 & $150.8-190.6$ & 174.0 & & & & \\
\hline $91.4-103.9$ & 97.7 & $239.1-241.5$ & 240.3 & & & & \\
\hline $131.3-165.6$ & 154.2 & & & & & & \\
\hline
\end{tabular}

motion and OMA-ARMA analysis: $11.9-12.3,36.0-38.2$, $97.0-97.8,106.3-111.0,174.0-177.9,240.0-245.0 \mathrm{~Hz}$.

\section{Conclusions}

Modal and harmonic analyses of a two-dimensional finite element (FE) model of the human hand-arm system are presented. Two boundary conditions were considered: the first is a fixed shoulder condition and the second is a model with the trunk to permit shoulder motion. The resonant frequencies were compared with those estimated from the measured experimental transmissibility responses and operational modal analysis using the autogressive moving average technique (OMA-ARMA). The results showed that the model that permits shoulder motion is a better model since the some of the derived resonant frequencies are closely related to the resonant frequencies determined from measured transmissibility responses and OMA-ARMA technique. Furthermore, the resonant frequency around $12 \mathrm{~Hz}$ was present in the responses of this model but not in the model with fixed shoulder. Animation of the second mode $(13.4 \mathrm{~Hz})$, corresponding to resonant frequency of about $12 \mathrm{~Hz}$, for the model that permits shoulder motion showed that the entire hand-arm system was subjected to repeated extension/compression in the $z_{h}$-axis. This frequency $(12 \mathrm{~Hz})$ is close to the frequency of maximum weight $(12.5 \mathrm{~Hz})$ in the weighting recommended in the current International Standard Organization (ISO 5349-1, 2001) for the assessment of hand-arm vibration syndrome.

An improved finite element model of the human handarm system may be used to study stress/strain distribution in different substructures of the hand-arm system. This may give useful information about hand-arm injury mechanism, the understanding of which may assist in deriving appropriate frequency weightings for the assessment of different components of the hand-arm vibration syndrome. 
Table 5. Comparisons of resonant frequencies of the human hand-arm system derived using different methods.

\begin{tabular}{|c|c|c|c|}
\hline $\begin{array}{c}\text { Measured } \\
\text { transmissibility }\end{array}$ & $\begin{array}{l}\text { FE model with } \\
\text { shoulder motion }\end{array}$ & $\begin{array}{l}\text { FE model with } \\
\text { fixed shoulder }\end{array}$ & $\begin{array}{l}\text { OMA- } \\
\text { ARMA }\end{array}$ \\
\hline \multicolumn{4}{|l|}{2.6} \\
\hline 7.4 & & & 7.8 \\
\hline 11.9 & 12.0 & & 12.3 \\
\hline 23.5 & & & 27.8 \\
\hline 36.6 & 36.0 & 37.0 & 38.2 \\
\hline 43.7 & & & 45.7 \\
\hline 52.4 & & & 55.2 \\
\hline 66.4 & & & 63.0 \\
\hline 76.6 & & & 78.5 \\
\hline 97.7 & 97.0 & & 97.8 \\
\hline 100.1 & 103.0 & & \\
\hline 106.3 & 111.0 & 107.0 & 109.1 \\
\hline 144.5 & & & 145.7 \\
\hline \multicolumn{4}{|l|}{154.2} \\
\hline 165.1 & & 166.0 & 168.1 \\
\hline 174.0 & 178.0 & & 177.9 \\
\hline \multicolumn{4}{|l|}{215.0} \\
\hline 240.3 & 245.0 & & 240.0 \\
\hline 251.6 & & & 255.5 \\
\hline 342.0 & & 348.0 & 341.8 \\
\hline 437.5 & & & 439.2 \\
\hline
\end{tabular}

Acknowledgements. This study is made possible by the Postdoctoral Fellowship awarded to the first author by the Natural Sciences and Engineering Council of Canada (NSERC). The authors therefore acknowledge the support of NSERC.

\section{References}

[1] M. Bovenzi, Exposure-response relationship in the handarm vibration syndrome: an overview of current epidemiology research, Int. Arch. Occup. Environ. Health 71 (1998) 509-519

[2] Y. Aldien, P. Marcotte, S. Rakheja, P.-É. Boileau, Influence of hand-arm posture on biodynamic response of the hand-arm exposed to $z_{h}$-axis vibration, IJIE 36 (2006) 45-59

[3] T. Nilsson, L. Burström, M. Hagberg, Risk assessment of vibration exposure and white fingers among platers, Int. Arch. Occup. Environ. Health 61 (1989) 473-481

[4] ISO 5349-1, Mechanical vibration and shock Measurement and evaluation of human exposure to mechanical vibration, International Organization for Standardization, 2001

[5] M. Thomas, Y. Beauchamp, Development of a new frequency weighting filter for the assessment of grinder exposure to wrist-transmitted vibration, 22nd ICC\&IE, 1997 Cairo, Egypt, Dec 20-22, 4p.

[6] S. Rakheja, J.Z. Wu, R.G. Dong, A.W. Schopper, A comparison of biodynamic models of the human hand-arm for applications to hand-held power tools, J. Sound Vib. 249 (2002) 55-82

[7] S.A. Adewusi, S. Rakheja, P. Marcotte, Biomechanical Models of the Human Hand-arm to Simulate Distributed Biodynamic Responses for Different Postures, Int. J. Ind. Ergon. 42 (2012) 249-260

[8] S. Adewusi, M. Thomas, H. Vu, Natural frequencies of the hand-arm system using finite element method,
Proceedings of the 4th American Conference on Human Vibration, Hartford, Connecticut, USA, June 13-14, 2012, 17-18

[9] V.H. Vu, M. Thomas, A.A. Lakis, L. Marcouiller, Operational modal analysis by updating autoregressive model, Mech. Syst. Signal Process. 25 (2011) 1028-1044

[10] J.Z. Wu, R.G. Dong, S. Rakheja, A.W. Schopper, Simulation of mechanical responses of fingertip to dynamic loading, Med. Eng. Phys. 24 (2002) 253-264

[11] S.A. Adewusi, S. Rakheja, P. Marcotte, J. Boutin, Vibration transmissibility characteristics of the human hand-arm system under different postures, hand forces and excitation levels, J. Sound Vib. 329 (2010) 2953-2971

[12] D.D. Reynolds, E.N. Angevine, Hand-arm vibration. Part II: vibration transmission characteristics of the hand and arm, J. Sound Vib. 51 (1977) 255-265

[13] H. Sakakibara, T. Kondo, M. Miyao, S. Yamada, T. Nakagawa, F. Kobayashi, Y. Ono, Transmission of handarm vibration to the head, Scand. J. Work Environ Health 12 (1986) 359-361

[14] G.J. Loren, R.L. Lieber, Tendon biomechanical properties enhance wrist muscle specialization, J. Biomechanics 128 (1995) 791-799

[15] C.N. Maganaris, J.P. Paul, In vivo human tendon mechanical properties, J. Physiol. 521 (1999) 307-313

[16] D.C. Wirtz, T. Schiffers, T. Pandorf, K. Radermacher, D. Weichert, R. Forst, Critical evaluation of known bone material properties to realize anisotropic FE simulation of the proximal femur, J. Biomech. 33 (2000) 1325-1330

[17] J.H. Dong, R.G. Dong, S. Rakheja, D.E. Welcome, T.W. McDowell, J.Z. Wu, A method for analyzing absorbed power distribution in the hand and arm substructures when operating vibration tools, J. Sound Vibr. 311 (2008) 1286-1304 